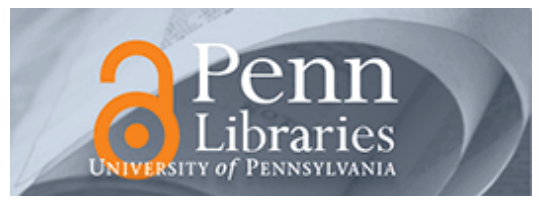

University of Pennsylvania ScholarlyCommons

\title{
The Impact of Differing Orientations of Librarians on the Process of Children's Book Selection: A Case Study of Library Tensions
}

Joseph Turow

University of Pennsylvania, jturow@asc.upenn.edu

Follow this and additional works at: https://repository.upenn.edu/asc_papers

Part of the Collection Development and Management Commons, and the Communication Commons

\section{Recommended Citation}

Turow, J. (1978). The Impact of Differing Orientations of Librarians on the Process of Children's Book Selection: A Case Study of Library Tensions. The Library Quarterly, 48 (3), 276-292. Retrieved from https://repository.upenn.edu/asc_papers/414 


\title{
The Impact of Differing Orientations of Librarians on the Process of Children's Book Selection: A Case Study of Library Tensions
}

\author{
Abstract \\ This paper represents an attempt to apply current organizational theory to the understanding of a large \\ juvenile library system's selection goals and guidelines. Writings on goal conflict within organizations \\ suggest that the two groups characteristically involved in a large library's book selection process, the \\ coordinators and branch librarians, would display differing orientations toward the process which would \\ result in conflicting objectives and organizational tensions. A case study using nonparticipant \\ observation, interviews, and a questionnaire survey was carried out to examine this hypothesis. The \\ findings challenge the traditional view of forces guiding book selection in a children's library \\ Disciplines \\ Collection Development and Management | Communication
}




\title{
THE IMPACT OF DIFFERING ORIENTATIONS OF LIBRARIANS ON THE PROCESS OF CHILDREN'S BOOK SELECTION: A CASE STUDY OF LIBRARY TENSIONS
}

\author{
Joseph Turow
}

This paper represents an attempt to apply current organizational theory to the understanding of a large juvenile library system's selection goals and guidelines. Writings on goal conflict within organizations suggest that the two groups characteristically involved in a large library's book selection process, the coordinators and branch librarians, would display differing orientations toward the process which would result in conflicting objectives and organizational tensions. A case study using nonparticipant observation, interviews, and a questionnaire survey was carried out to examine this hypothesis. The findings challenge the traditional view of forces guiding book selection in a children's library.

There is a great deal of writing on children's books, and much of it is related to the selection of titles for public and school libraries. However, while specific reviews of juvenile titles abound and general, normative prescriptions for the selection of titles are issued regularly, relatively little literature exists on the organizational factors which guide librarians to purchase certain books over others. Studies which do deal with organizational influences on selection (for example $[1,2,3,4,5]$ ) are generally directed toward the question of library censorship, a sanction that is only one facet of the overall selection process. Moreover, such studies tend to concentrate on quantifiable conclusions about large, often unrelated populations. No work could be found which views a children's library as an organizational system and attempts to chart the influences which guide book-purchasing activities of librarians as they interact within that system.

The investigation to be reported here represents an attempt to apply the holistic, interactional perspective of current organizational theory to the understanding of a large juvenile library system's selection goals and guidelines. Through nonparticipant observations, interviews, and a questionnaire survey, the selection interests and activities of the library personnel were examined. As expected from organizational theory, two different orientations toward the library world were found among the two groups of librarians in the system, orientations which reflected the

[Library Quarterly, vol. 48, no. 3, pp. 276-292]

(C) 1978 by The University of Chicago. $0024-2519 / 78 / 4803-0002 \$ 01.80$ 
confluence of different-and often conflicting-intraorganizational and extraorganizational pressures. The different selection goals of the two groups, the process of new-book selection to carry out the goals, the actual selection and rejection of new titles, and even the images librarians had of the children who read the purchased titles were seen to result from these orientations, from the tensions they raised, and from structural as well as procedural attempts to mitigate those tensions. The study's findings raise some important challenges to the traditional view of forces guiding children's book selection and point to unexplored areas for further research.

\section{The Conceptual Framework}

Asking about the influences which guide the members of any organization to perform certain activities necessarily involves asking about the organizational goals they hold, the factors which shape those goals, and the consequences of those goals for organizational operations. Theorists have pointed out that few, if any, organizations have only one goal. In fact, complex organizations often have subunits that develop interests and goals which are independent of the aims of other subunits and sometimes even of the organization as a whole (see especially [6]). Furthermore, writers agree that in such common goal differentiations lie the seeds of intraorganizational conflict. March and Simon [7, p. 121], for example, have written that a necessary condition for intraorganizational conflict exists when subunits involved in joint decision making have different perceptions of reality and (possibly as a consequence of such varying orientations) different goals.

Pondy [8], moving somewhat further along these lines, has specified three types of conflict-bargaining conflict, bureaucratic conflict, and systems conflict - that can be expected among various types of subunits in formal organizations. Bureaucratic conflict, for example, takes place between parties involved in a superior-subordinate relationship. Because subordinates cannot rely on superiors always to identify sufficiently with subordinate goals, a measure of autonomy becomes important to subordinates who resist attempts by superiors to control some of their subunit operations.

Pondy sees conflict as a dynamic process that advances from a "latent" stage (characterized by the existence of conditions necessary for conflict), to stages in which organizational tensions are both felt and perceived by members, to a stage in which those tensions erupt into "manifest conflict." However, he notes that just as an organization tends to evolve ways to routinize nonargumentative decisions, so it develops ways of 
managing tension in order to minimize the frequency of conflict and reduce its severity when it flares. He points out that "minor conflicts" generate pressures toward a resolution which does not change fundamental organizational relationships. On the other hand, "major conflicts" ultimately force alteration or dissolution of those relationships.

The foregoing paragraphs are relevant to an understanding of factors which guide children's book selection in a large public library. As a formal organization, a library can be expected to exhibit the same kinds of tensions that are evident in other formally structured entities. Concern in a library with interaction between subunits is especially relevant because the activity of book selection in a large library is characteristically the joint decision making concern of two groups - the branch librarians and coordinating librarians who oversee this process. Using the theory outlined above, it can be predicted that an investigation of book-selection goals held by the two groups would reveal competing orientations toward book selection which result in conflicting objectives and consequent organizational tensions. It can further be predicted that, in Pondy's terms, these tensions lead to latent bureaucratic conflict that is made manifest at intervals by the breakdown of routinized tensionmanagement procedures.

\section{The Library Studied}

A case study seemed the best way to carry out an initial examination of these hypotheses, despite the problem of generalizing findings from a single library. It was felt that an intensive investigation into the workings of one library system could reveal tensions and procedures that a necessarily more superficial survey of many systems might miss. A large city's public library was the site of research conducted during the fall of 1975 and the spring of 1976 . The city is an ethnically diverse urban center that has more than a million people and is located in the northeastern section of the United States. Its public library system, founded before the turn of the twentieth century, has two major book-buying and distributing arms oriented toward different audiences - the Adult/Young Adult Services Division and the Juvenile Services Division. The entire library has about 3 million volumes in stock nearly a million of which belong to the juvenile division. In 1975, that division was responsible for about $1 \frac{1}{2}$ million book loans.

The Juvenile Services Division and the Adult/Young Adult Services Division share space in the library's fifty sections, which include forty-six branches, a bookmobile service, a service which deposits books in schools with no libraries and which lends books to the handicapped, a regional branch, and a central branch. The branches are meant to serve specific 
neighborhoods within the city; the three special service areas are designed to make the library more accessible to children and adults who cannot easily use it; and the regional library is equipped to serve the broad and specialized needs of a large district far from the central branch. The nerve centers of the Juvenile Services and the Adult/Young Adult Services Divisions are their system coordinating offices (SCOs), which oversee work carried out in the units. The purpose of both SCOs is to direct divisional planning and policy; to coordinate the selection, processing, and purchasing of books, records, and film strips in all units; and to initiate and carry out various entertainent programs for their audiences throughout the year.

The head of the juvenile SCO controls the entire range of the juvenile division's activities. Although she is ultimately responsible to the directors and associate director of the entire library, the head of SCO is a nationally known figure who has been at her position for over a decade and, according to the director, has considerable autonomy in determining policies within the juvenile division.

The head of SCO delegates much of the day-to-day responsibility of the book, record, and film selection processes to her head of book selection who, in turn, has two coordinators of lower rank to help her. An "area coordinator" also plays an active role in the selection of books, particularly in the regional library and the branches surrounding it. The coordinators are former branch librarians with several years' experience who took special civil service tests to work in the SCO and advance to one of three levels there.

There are also three professional grades in the branches. Beginners (who must have a master's degree in library science) start at level 1 and by passing competitive examinations may advance to assistant branch head (level 2) or branch head (level 3) when an appropriate position is vacant. It should be noted that not every branch has a children's librarian. Insufficient funding and difficulties of staffing the central branch have resulted in forty-five professional librarians being located in only forty-four of the fifty sections (the central branch has two professional librarians). In the branches without librarians, lower-paid "technicians" care for the juvenile collection and help children choose books.

\section{The Book Selection Procedure}

The selection of books that end up on branch shelves takes place through a two-stage process. In the first stage, books are examined for general acceptability to the juvenile division as a whole. Every month the branch librarians and the coordinators choose (or, more rarely, are assigned) newly arrived titles to review in writing for the next Book 
Selection Committee meeting, which is held monthly from September to June. After perusing the books, this committee of eleven (which is chaired by the head of book selection and is comprised of her two assistants, the area coordinator, and an annually rotating panel of branch librarians) decides whether any reviewer's recommendations on system acceptance or rejection of a title should be contested. A second careful review by another librarian might be suggested. The majority decision by the committee must be approved by - and can be vetoed by-either the head of book selection or the head of SCO.

After these selection decisions are made, a list is drawn up which indicates the final status of each book. The branch librarians then come to the SCO to decide which of the accepted books they would like to buy for their particular branches. Branches without children's librarians have their books bought for them by the SCO librarians, the regional area coordinator, or the additional librarian in the central branch. During this branch selection process, the librarians are encouraged to examine the books, as well as to read the staff review(s) of each. When all the branch orders are completed (at the end of the month), they are sent to the library system's acquisitions department, where they are consolidated and assigned to a jobber (or jobbers). The book-selection head estimates that most titles end up on branch shelves approximately six months after publication date.

\section{The Method of Study}

As noted earlier, the aim of the present study was to chart the influences guiding the juvenile librarians' book selection activities. More specifically, the purpose was to understand their selection goals, delineate the organizational and extraorganizational factors that shape those goals, and note how those goals are translated into specific selection guidelines and activities. Four methods were used to achieve this aim - the interview, the questionnaire survey, nonparticipant observation, and the examination of formal library documents. The first two were the most systematic and elaborate. Interviews were conducted with all four coordinators and fifteen of the branch librarians; the one-third sample of branch personnel was chosen through an accidental selection of those visiting SCO to select new books. The questionnaire was mailed to all librarians (including the nineteen interviewed) to fill out anonymously and return by mail.

\section{The Interviews}

Most interviews ranged from forty-five minutes to an hour in length, though several were longer and a few were shorter. In the first part, the 
librarian was asked to describe her professional activities and goals. The second part dealt with specific details of book selection at each stage of the two-stage operation. First, for each of nineteen characteristics of titles or groups of titles that might be relevant to the interviewee during the SCO book review, interviewees were asked: (1) how influential they thought they themselves were in affecting decisions involving each characteristic at the SCO level; (2) how important they thought each characteristic was when they were themselves making decisions at the SCO level; and (3) what general guidelines they themselves followed with respect to each characteristic and why in making selection decisions (see table 1). Then, similar questions about the nineteen characteristics were asked regarding the librarian's branch selection activities. The section ended with a query about "any controversial issues on children's books that have affected [the librarian and her] work during the past year," followed by another on the librarian's image of "the people who read" her books and the way she arrived at that image. ${ }^{1}$

The third part of the interview attempted to gauge the librarian's contact with members of the publishing industry, her opinions about children's books currently published, and her feelings about the titles

TABLE 1

Title and List Characteristics Influencing the Review' Process

1. The size of the selection list.

2. The relative selection of fiction and nonfiction titles.

3. The relative selection of fantasy and reality titles.

4. The relative selection of books for "general" audiences vs. titles for particular ethnic and/or racial groups.

5. The relative selection of books for different ages and/or grades.

6. The author and illustrator.

7. The subject of the book.

8. The plot.

9. The illustrations.

10. The characters and the way they are portrayed (probe on preferences regarding racial mix; animal vs. people; sexual mix).

11. The moral point of view.

12. The style (probe on poetry vs. prose; first or third person narration; use of curse words; vocabulary difficulty control).

13. The accuracy.

14. The size of the book (probe on dimensions; length).

15. The binding of the book.

16. The cover art of the book.

17. The overall design (probe on typography; margin sizes; frontispiece design; quality of paper).

18. The price.

19. The paperback format.

1. The female pronoun is used because all of the librarians in this study are women. 
her library accepts and rejects from among those published. The interviewee was asked about meetings with editors and salespeopleand about the value she places on such meetings; she was asked if there are any types of books she wants but cannot find; and she was asked if, in her opinion, there have been any books or types of books which have been rejected by the juvenile division but should have been accepted. These questions were followed by a last group which asked about the librarian's professional background-her rank, number of years worked, most recent degree, undergraduate major, affiliation with professional associations, and conference attendance.

Each interview was recorded, and the results were transcribed. Analysis was conducted by grouping all answers to each question together and comparing them for similarities and differences of response. Answers by coordinators and branch personnel were grouped separately and compared, as were answers by branch personnel of different ranks and years of experience. An interesting picture resulted of influences which shape particular selection goals and guidelines within the Juvenile Services Division.

\section{The Questionnaire Survey}

A questionnaire survey attempted to ascertain the generalizability to the system as a whole of what had been found about the division's book selection process as a result of the interviews. The detailed questionnaire (completed by thirty-five librarians) was similar in thrust to the interview schedule. In the first part, each respondent was presented with a list of forty influences - "people, groups, facts, and feelings" - that were mentioned by at least five of the interviewees as relevant to library selection activities at the SCO level, the branch level, or both. ${ }^{2}$ The respondent

2. The influences were: The total book-buying budget of the division; your branch's book-buying budget; the opinions of SCO librarians who read the book; the Kirkus review of the book; reviews of the book in professional review media other than Kirkus; your opinion of the librarian who wrote the SCO review (applies to branch level only); the reputation of the author; the reputation of the illustrator; the reputation of the book publisher; the head of SCO; the head of book selection at SCO; your personal likes and dislikes; your branch's current circulation figures; your general philosophy of what children ought to read; your general impressions about what [the city's] children like to read; your general impressions about what children who come to your branch like to read; ethnic and racial minorities from around the city; ethnic and racial minorities from your branch area; older children who are slow readers; advanced readers; the potential popularity of the book in terms of circulation; the extent to which the book is of very high quality; the size of the month's selection list; the cost of the book; the extent to which the book will balance your collection; the moral point of view in the book; the library's trustees or directors; parent-teacher organizations; library science students who borrow books; parents who borrow books; teachers who borrow books; school assignments given to students; the books which school libraries 
was asked to note whether each influence is usually very important, somewhat important, or not important at all when reviewing books for SCO. Similarly, she was asked to note the importance of those same influences when performing branch-level selection.

Part 2 of the questionnaire focused on the choosing of books for a branch and on some of the activities that take place in the branch. The respondent was asked about the adequacy of her book-buying budget, about any conflicts she feels between buying potentially popular titles and buying high-quality titles, and the direction in which she would prefer to resolve such a conflict if it were to arise. A question about the desirability of introducing the "Nancy Drew" series (which has been rejected consistently by the library) was followed by two questions about the perceived importance of branch circulation statistics and several queries about the librarian's interactions with children and parents in the branch. In part 3 of the questionnaire, a series of questions was posed about the librarian's contacts with representatives of the publishing world and perceptions of her division's influence in that world. The final part consisted of the "background" questions asked in the interview, with the addition of queries about the general socioeconomic status and juvenile reading abilities in the respondent's branch area.

As in the case of the interviews, answers by coordinators and branch librarians were grouped separately and compared. Other background characteristics were also cross-tabulated with answers about influences and activities to ascertain if those characteristics were more likely than SCO or branch position to be associated with differences in response among the librarians. The survey results and the interview results on similar issues were compared. Conclusions from that analysis were supplemented by impressions from nonparticipant observation of library selection activities (including the SCO book review meetings, which were closed to the public) as well as by information from formal library documents about book selection procedures. The findings converged to reveal a fascinating picture of selection tensions rooted, ultimately, in librarians' competing orientations toward the library world.

\section{Orientations to Selection}

As predicted, the librarians' orientations were closely associated with the coordinator and branch positions within the library system and, by

carry; the potential use of the book in a "book talk"; the use of the book in a book fair; potential complaints from parents; people or pressures from city or state government; publishers' book fairs; your training in library school; promotional material from the publisher. 
extension, with the structure of the juvenile division of the system itself. The different outlooks connected to this bureaucratic structural separation can be described in the "cosmopolitan" and "local" terms which Merton [9] used to distinguish the orientations of different types of opinion leaders. The SCO librarians were cosmopolitan in perspective; that is, they were interested in and committed to the larger world of librarianship and publishing, and they saw the whole library's importance in terms of that world. By contrast, the branch personnel had a local orientation. They tended to be much less interested in outside matters and saw the needs of individual branch locales as the most important areas of concern.

This difference in orientation was closely tied to a differential emphasis on selection goals. The SCO librarians tended to stress the importance of a work's "quality," while branch librarians tended consistently to stress the importance of a title's potential enjoyability or its potential "popularity." The specific meanings which librarians invested "quality" and "popularity" will be reviewed later in this paper as influences which guided different approaches to selection are discussed. Nevertheless, a quantitative indication that popularity was indeed more important to branch personnel than to coordinators is possible: While twenty-nine (91 percent) of the thirty-two branch librarians who responded to the branch questionnaire listed general impressions of what children like as "very important" in the selection of books for their branch, none of the three coordinators (who responded to that part of the questionnaire in their capacities as book buyers for outlets without children's librarians) thought it more than "somewhat important."

\section{Influences Shaping the Different Orientations and Goals}

This dissimilarity of orientation and emphasis on selection goals can be traced to the differential impact of certain organizational influences upon the two groups of librarians. One influence that impinges more upon branch personnel than coordinators is the allocation of 30 percent of the book-purchasing funds in direct proportion to a branch's circulation figures. While the coordinators tended to play down the importance of this factor (and stressed that discretionary cash is often used to help branches with low circulation), some branch librarians were not sanguine about their chances of maintaining or increasing their budgets without maintaining or increasing their circulation. Of the thirty-five respondents, eight (23 percent) said that current circulation figures are "very important" considerations when they select books for their localities, 
while fourteen (43 percent) described this information as "somewhat important" (eleven answered "not important," and two stated no opinion). One librarian who had worked in the system for twenty-two years suggested that concern over circulation is more widespread than these responses indicate when she observed that every branch librarian "is under pressure to a certain extent to keep circulation up." For the branch librarians interviewed who were most aware of it, this pressure was judged a book selection requirement. They reasoned that the allocation of funds according to circulation directs them toward the consideration of only minimum standards of quality in a search for books which promise to turn over most quickly.

The different outlooks of coordinators and branch librarians were seen to be reinforced by their varied contact with the publishing world. Data from the questionnaire and interview surveys indicate that, while all the coordinators frequently attend library conferences, are often in contact with editors and other publishers' representatives, and know quite a bit about current happenings within the children's book industry, the majority of branch librarians rarely go to conferences, speak to publishing people, or know very much about the industry or its imprints. The head of SCO noted she is well aware of promotional tactics that impinge upon her and her SCO associates during their interactions with publishers' representatives. She considered, however, that influences are two way; by allowing publishers to ask favors of her (such as the review of manuscripts) and promote books to the branch libraries through her, she receives the opportunity of making a mark on their activities and, in essence, of helping them define quality. In fact, the desire to be influential in heralding and defining quality within the publishing and library world was seen by the coordinators as an important reason for maintaining the library system's national reputation as a repository for the best juvenile titles.

Still another important influence seen to shape the difference in orientation and emphasis on selection goals was the close interaction of the branch personnel with children, an interaction which the SCO librarians, because of the administrative nature of their positions, do not enjoy. Several branch interviewees noted that working on the floor, listening to children's requests, helping students with school assignments, and dealing firsthand with the low reading abilities of many of them yield a perspective which shifts the foremost emphasis of book selection from quality to popularity. One librarian echoed the view of a number of her branch colleagues when she noted coordinators "don't get out on the branch floors that much. So there is sometimes a gap in what the librarians on the floor perceive and what they [that is, the coordinators] think is going on. I think there is a tremendous gap 
sometimes." Branch librarians as a group were aware of this difference in orientation, and many saw their primacy of response to children as determining it. $^{3}$

\section{The Goal of Quality}

Not all influences impinging upon the branch librarians were seen as explaining the difference in primary selection goals between them and the coordinators. Two major, complementary influences were observed as pushing the branch librarians in the direction of recognizing the importance of quality to the extent that fourteen ( 44 percent) noted it as "very important" for branch selection, sixteen (50 percent) said that it is "somewhat important," and only one considered it "not important" at all. One influence, library-school training, was spontaneously noted by a few of the interviewed. Although that experience was considered "very important" for branch selection by only seven (20 percent) of the survey respondents, nineteen others (57 percent) thought it "somewhat important."

It was in library school that many guidelines for quality were formally introduced to the respondents. Librarians stressed that every book's acceptance is contingent on its moral and developmental appropriateness for the intended audience. There was a general unanimity among coordinators and branch personnel regarding "moral point of view." They disapproved of books they considered obviously dogmatic or

3. The reader will observe that such seemingly important extralibrary and extradivisional bodies as parent-teacher organizations, the city and state governments, and the library director and trustees have not been noted as structuring the orientations or primary selection goals of the system's librarians. This ommission is in accordance with the failure of any interviewee to indicate that they were significant (except with regard to the routine, initial provision of funds to SCO) and in line with their being among the factors considered "not important" by over 70 percent of the questionnaire respondents. It should be pointed out, however, that these answers do not reflect the implicit, encompassing influences of the abovementioned entities as the library system's key patrons (the city and state governments), as the pressure groups which impinge upon the patrons (PTAs and others), or as the system's managerial links between its patrons and its operations (the director and the trustees). One may therefore speculate that if these and other key establishment figures experienced displeasure with the division's approach to book selection, their displeasure would, at the very least, be taken as an invitation seriously to reexamine (and, perhaps, restructure) the entire process. When interviewed, however, the library director did note that the reputation and expertise of the SCO head have led him to give virtual autonomy in selection to her. And, since there has not been a critical incident in the recent past in which extraorganizational factors have significantly challenged the division's activities, the librarians had no cause to consider patrons or pressure groups when reviewing or choosing books. 
moralistic. They pointed out that themes involving drugs, heterosexual activity, homosexuality, abortion, racial discrimination, race relations, and gang warfare - along with curse words - have been found in titles which the division has accepted. However, it seems that titles on such topics have been confined predominantly to middle- and upper-juvenile readers (grades four through eight) and that the librarians believe the books should contain thoughtful, positive moral positions, even if they do not contain "happy endings." Several interviewees also recalled that certain types of books are specifically prohibited by the SCO selection policy handbook. "How-to" manuals on subjects (such as judo and hypnotism) which can "cause serious injury unless carefully supervised by an expert" are barred, and titles relating to specific religious teachings or practices are excluded, since "the library considers the child's spiritual development as primarily the responsibility of his home and church." High quality, though related to such moral and developmental values, was particularly associated with literary, highly aesthetic, and distinctive books. By the same token, cartoonish illustrations and series book formats - popular features of department store juveniles - were judged formulaic and generally unacceptable.

Changing perceptions of quality in the publishing world and the national library scene were communicated to the branch personnel by the coordinators. The SCO provided continual reinforcement for the general goal of quality in periodic formal and informal meetings between itself and branch librarians. Pragmatic incentive for branch librarians' purchase of titles highly approved by the coordinating office was found in the coordinators' annual inspection of the branches and scrutiny of all large book-replacement orders. The purpose of this inspection was to maintain control over the reputation of the entire collection.

It should be stressed, however, that despite these influences branch librarians regarded quality as secondary to popularity in guiding selection. Moreover, while library-school training and reinforcement of the necessity of quality by the coordinators did make considerations of literary value important in establishing minimum standards for title acceptability, those influences did not seem to shift the branch personnel toward a more cosmopolitan orientation. Most remained staunchly "local" and were quite aware of the generally conflicting orientation of their superiors. The following is a representative remark: "I think they [that is, the coordinators] are concerned a little too much with quality over popularity. Not just quality, but name authors and publishers and illustrators, and things like that. Out in the branches, we don't think about publishers, but in [SCO] they do and they know what kinds of publishers are doing what kinds of stuff." 


\section{Selection Orientation and Audience Images}

The local and cosmopolitan orientations of the two groups of librarians and the different selection goals associated with those orientations were seen to structure different approaches to, and conceptions of, the children who read the library system's books. The branch librarians tended to speak about children in terms of catagories - sex, age, reading level, and sometimes race-that had to be met during selection. They used those categories to purchase books according to a notion of "balance" - the choosing of titles from a book list so as to cover a wide range of audience groups. Popularity was often defined with balance in mind. It was taken to mean the high circulation of a title among the particular audience category for which it was intended. Thus, for example, branch personnel said they try to choose monster books, joke books, car books, and books on World War II for older boys while also taking care to get modern romances and some types of fantasy for older girls. In general, the lower a librarian's budget, the more she characterized as difficult an adherence to the idea of balance regarding a great number of audience categories. In such cases, the children were placed into only one or two categories for making selection decisions.

In contrast to the branch personnel's demographic view of its readership, the SCO librarians tended to stress a generalized conception of children as sharing particular needs - such as the need to be enriched by different types of special aesthetic experiences. Since the coordinators had worked in the branches at one time and were continuing to order books for outlets without children's librarians, they recognized pragmatically the necessity for audience categories. However, the specificity with which branch librarians discussed their selection activities in terms of these categories was not found among coordinators, who admitted they don't get out on the floor very much and have to rely on feedback from branch personnel for information about what is popular.

In one respect, then, the coordinators' inability to appreciate the branch personnel's perspective on the audience was related to their inability to identify comfortably with that group's local orientation. However, the SCO librarians' emphasis on the aesthetic or other needs of children could also be seen to derive from their cosmopolitan viewpoint and its associated selection goal of "quality." The head of SCO interpreted the branch people's penchant for clearly popular titles as simply indicating they prefer to choose "what seems to be what children want by what they say they want or take out," in view of the choices they have at the time. She said unusual titles that will give children a feel for true artistry can be successfully introduced to them, particularly if a good librarian is doing the experimenting. 
Orientation and the Selection Process

It will be recalled from the theory outlined at the outset of this paper that an organization can be expected to evolve ways of routinizing the management of structural tensions so as to minimize the frequency and severity of manifest conflict. In the case of the library system under discussion, overt tensions because of different orientations, selection goals, and audience images were both highlighted and mitigated by the division's two-stage (system-level and branch-level) selection routine.

Sources and Surceasers of Tension

Each level of the two-tiered procedure called attention to one of the competing primary requirements for selection. Data from the questionnaire survey corroborated as widespread the opinions of several interviewees that their main concern when reviewing a book for system-level selection is "the extent to which the book is of very high quality": Twentythree (72 percent) of the responding branch librarians thought this criterion "very important" at this stage of reviewing while only eleven (34 percent) felt that way about general impressions of what the city's children like to read. In striking contrast, when asked about branch-level selection thirty (94 percent) of the branch personnel felt that general impressions about what children in their branch areas like to read are "very important," while only thirteen (41 percent) thought the "high quality" statement rated that description.

Despite their general acceptance of the quality goal as a basis for system-level selection, several branch personnel evidenced some annoyance with coordinators' activities at that stage. They referred to instances in which the head of SCO overrode their unfavorable reviews (as well as the book selection committee's concurrence with the unfavorable reviews) and accepted titles allegedly because of friendship with or personal esteem for an author or illustrator. The branch librarians said that, in response to such actions, they simply do not buy those titles for their branches; the books are purchased only for the central library. More distressing, the interviewees noted, are the somewhat more frequent cases where titles they and the book selection committee have reviewed favorably are vetoed by the book selection head or the head of SCO for reasons of unacceptable quality.

Generally speaking, however, the process of book selection within the library system was considered flexible enough to ensure coordinator control over minimum requirements for acceptability (which are ordinarily agreeable to branch personnel) while also mitigating much of the tension between the two groups as to whether quality or popularity should come first. The tension that arises over titles of very high quality 
which branch personnel believe will not be popular in their branches is alleviated by allowing those librarians to decide upon the particular books to purchase for their branches. At the same time, the chance that a book which is clearly unacceptable to coordinators will be deemed acceptable to branch librarian reviewers (and expose this undercurrent of tension) is reduced through the private screening of books by the head of book selection before they are even put up for SCO review. The book selection head explained this activity, in which she excludes titles which obviously do not meet her minimum standards, with a rhetorical question: "Why waste someone's time with something from a cheap press that I know we don't need?"

\section{Open Conflict Regarding Selection}

Despite the general reduction of tension which the two-tiered selection process encourages, flare-ups which force the librarians of the system to confront their differences in orientation do occur. During the course of this study, for example, manifest conflict arose over the acceptability of the "Nancy Drew" series, picture books by Richard Scarry (currently the best-selling children's book author-illustrator in book and department stores), and easy readers with fixed word lists. Significantly, these books had been consistently rejected by SCO while being constantly requested of the branch librarians by many children and parents who had become familar with them through nonlibrary sources.

The heads of SCO and book selection, who pointed out their experience in handling these matters, dealt with each of the three instances in a different manner. Since knowledge about the requests for easy word list readers had not yet pervaded the system, the book selection head felt that explanatory action was premature. She seemed confident, however, that such books, which she believed to have a consistently stilted style, will continue to be rejected. In the case of Richard Scarry's books, which the coordinators considered repetitious and cluttered, demand on the part of branch librarians had become so strong that, after two years of routine rejection, the coordinators agreed to accept one of his titles on a trial, ostensibly to gauge children's reactions to the books. Such a procedure indicates explicitly that the title involved is an exception and that a redefinition of the boundaries of quality has not occurred. It also gives notice that a precedent has not been made with regard to the evaluation of other Scarry books.

The coordinators refused to allow a test of the "Nancy Drew" series, since the individual titles are numbered and to accept one would be to invite children to ask for others. However, an angry letter signed by a large number of librarians asking SCO to allow purchase of "Nancy Drew" books caused the head coordinator to schedule a meeting to deal with the matter more generally. Convinced that the petitioners had not 
read a book from the series since childhood, and evidently aiming to show the librarians that the newer editions are even worse than the older ones, the head of SCO asked all of them to read an old and new "Drew" book for the meeting. Each person was asked to stand and state her opinion of the books. It is, of course, impossible to know how the format of the gathering (with its requirement of a public profession) influenced the responses of the branch librarians to the books. At any rate, none of them spoke in favor of "Nancy Drew," at the meeting or in answering this study's questionnaire. Speaking about the "Nancy Drew" series, the head of SCO gave a pragmatic monetary reason for wanting to reject those books: if the system accepted them, the branches would continually be buying the many titles in the series and replacing them as they wore out. The substantial sums invested in this way would preclude purchase of high-quality books which deserve to be bought. In essence, then, SCO's authority was used to manage this and the other conflicts so that the cosmopolitan orientation of the coordinators and its attendant selection goal of quality were ultimately more influential in the system than the local orientation of the branch librarians and its selection goal of popularity.

\section{Concluding Remarks}

The findings of this study shed a somewhat unusual light on the book selection activity of children's librarians. Most writing on children's book selection is self-congratulatory in tone and implies that those connected with the distribution of juvenile titles through libraries are guided by a unanimous desire to create a reading environment for the child which will be the source of "everlasting growth, and delight" [10, p. 21]. The present study, through the instance of one large system, challenges this assumption by pointing to the pragmatic organizational and extraorganizational concerns which have important consequences for book selection through their influence on the orientation of librarians toward the selection process.

Organizational theory, it has been noted, points up the likelihood of bureaucratic tensions in all multiunit library divisions. Of course, examination of other systems is necessary to determine if the particular competing perspectives and goals observed in the system under study here can be found elsewhere and, if so, under what conditions. The findings of this study suggest that the adoption of a cosmopolitan or local orientation by a group of children's librarians depends on the relative influence of three factors - the extent of the group's contact with the "library world" (library-market publishers and library schools), the reading level and other relevant features of young people who visit the 
library, and the degree to which library funding is tied to circulation figures.

Greater awareness of organizational and extraorganizational pressures upon children's libraries will lead to a much better understanding of fundamental, though often quite implicit, concerns involved in the selection of books. This understanding will aid library administrators to confront and, if desirable, to alleviate certain tensions and conflicts within their systems. Moreover, an explicit recognition of competing orientations and goals might lead to more critical and novel questions about the purpose of children's librarianship and might spark ideas which will add new dimensions to the discussion of children's book selection.

\section{REFERENCES}

1. Broderick, Dorothy M. “'Problem' Nonfiction.” Library Journal 87 (October 1962): 3373-78.

2. Busha, Charles. The Attitudes of Midwestern Public Librarians towards Intellectual Freedom and Censorship. Ph.D. dissertation, Indiana University, 1971.

3. Eakin, May L. Censorship in Public High School Libraries. M.A. thesis, Columbia University, 1948.

4. Moon, Eric. “'Problem' Fiction.” Library Journal 87 (January 1962): 484-96.

5. Tamblyn, Eldon W. "They Play It Safe." Library Journal 90 (June 1965): 2495-98.

6. Selznick, P. "Foundations of the Theory of Organization." American Sociological Review 13 (January 1948): 25-35.

7. March, James G., and Simon, Herbert A. Organizations. New York: John Wiley \& Sons, 1958.

8. Pondy, Louis R. "Organizational Conflict: Concepts and Models." Administrative Science Quarterly 12 (September 1967): 296-320.

9. Merton, Robert K. "Patterns of Influence." In Communication Research, 1948-49, edited by Paul Lazersfeld and Frank Stanton. New York: Harper \& Bros., 1949.

10. Gross, Elizabeth H. Public Library Service to Children. Dobbs Ferry, N.Y.: Oceana Publications, 1967. 